\title{
Urgences
}

\section{Identités minuscules}

Numéro 17-18, octobre 1987

L'esprit des lieux

URI : https://id.erudit.org/iderudit/025437ar

DOI : https://doi.org/10.7202/025437ar

Aller au sommaire du numéro

Éditeur(s)

Urgences

ISSN

0226-9554 (imprimé)

1927-3924 (numérique)

Découvrir la revue

Citer ce document

(1987). Identités minuscules. Urgences, (17-18), 211-214.

https://doi.org/10.7202/025437ar

Ce document est protégé par la loi sur le droit d'auteur. L'utilisation des services d'Érudit (y compris la reproduction) est assujettie à sa politique d'utilisation que vous pouvez consulter en ligne.

https://apropos.erudit.org/fr/usagers/politique-dutilisation/ 


\section{IDENTITES MINUSCULES}

\section{PAUL-ANDRE BOURQUE}

Né à Montréal le 8 mai 1940, détenteur d'un doctorat en littérature française, il est l'auteur d'une thèse sur L'écriture dramatique pour la télévision: fiction, réflexion, essai. Il est professeur agrégé à l'Université Laval. Depuis 1974, il a travaillé à l'écriture de nombreux textes pour la télévision et la radio: adaptation de textes dramatiques, documentaires, entrevues, critique littéraire, etc. Il a en outre signé plus d'une soixantaine d'articles sur la littérature.

\section{LUC BUREAU}

Né dans la Beauce, il est diplômé de l'Université du Minnesota et professeur de géographie à l'Université Laval depuis 1971. Il a travaillé à de nombreux projets de recherche portant entre autres sur l'architecture populaire et l'aménagement du territoire, et collaboré à la rédaction de l'Atlas historique du Canada. En 1984, il a publié un essai intitulé Entre l'Eden et l'Utopie: les fondements imaginaires de l'espace québécois.

\section{DOMINGO CISNEROS}

Né à Monterrey, Mexique, en 1942, il est indien Tepehuane. Dans les années 1960 , il étudie l'art, l'architecture et le cinéma à Mexico. Après des voyages en Amérique latine, en Europe et dans les lles du Pacifique, il s'établit au Canada au début des années 1970. En 1974, il a travaillé au Collège Manitou, à La Macaza, au nord de Montréal. Il poursuit depuis une démarche artistique où interviennent les traditions amérindiennes chamaniques.

\section{RENE DEROUIN}

Né à Montréal en 1936, il est graveur sur bois. Il a fait des études en arts graphiques à l'Ecole des Beaux-Arts de Montréal et à l'Université de Mexico, et en design d'aménagement à l'Ecole des Hautes Etudes Commerciales de Montréal. Depuis 1967, il a participé à des expositions individuelles et collectives au Canada, en Suisse, en France, au Mexique, au Japon, etc. Il a réalisé des productions audio-visuelles. En 1970, il a fondé les Editions Formart. Il a été directeur du Conseil de la gravure du Québec.

\section{HELEN ESCOBEDO}

Née à Mexico en 1934, elle a fait ses études à l'Université Motolina de Mexico,. au Collège de la ville de Mexico et au Royal Collège of Art d'Allemagne. Elle a été directrice du Département des musées et galeries de la National Université of Mexico (1961-1978), recherchiste à I'UNAM, au département des Sciences humaines et membre fondatrice du laboratoire de recherche en Art 
Urbain, et directrice du Musée d'Art Moderne de Mexico. Elle a exposé en solo à Mexico, Oslo, Prague, etc. et réalisé de nombreuses pièces d'art urbain. Elle a participé à la réalisation de la pièce environnementale intitulée Espacio Escultorio. Elle a dirigé des ateliers et assumé des postes d'artiste résidente dans plusieurs universités des Etats-Unis.

\section{PAUL FAUCHER}

Né à Montréal en 1940, il étudie à l'Ecole d'Architecture de Montréal dont il a été diplômé en 1964. Il a travaillé à la division Génie et Architecture de l'Université de Montréal, et pour la société SORES, en Algérie. Depuis 1972, il travaille avec la firme Blouin et associés. Il a travaillé à la réalisation de plusieurs projets importants dont les installations de Mirabel, le Parc Olympique, le Parc historique de la Pointe du Moulin (lle Perrot), la restauration du Fort Chambly, la bibliothèque municipale de Terrebonne, le Centre d'accueil Armand-Lavergne, etc. Il a reçu de nombreuses distinctions: Mention, Distinction et Prix d'Excellence de l'OAQ.

\section{PIERRE LAPLANTE}

Né à Montréal en 1946, il a obtenu une licence en géographie à l'Université de Montréal en 1970, et une maîtrise en géomorphologie de l'Université Laval en 1974. Il est actuellement professeur de géographie à l'UQAR. Entre 1975 et 1980 , il a été coordonnateur scientifique du projet du Musée d'histoire naturelle de Miguasha. En 1980, il rédige un mémoire sur la création du Parc de la Gaspésie. Il a publié en 1984 La forme de la terre.

\section{PAUL CHANEL MALENFANT}

Né à St-Clément (Rivière-du-Loup) en 1950, il a obtenu un baccalauréat en Études françaises et une maîtrise ès Lettres de l'Université de Montréal, ainsi qu'un doctorat ès Lettres de l'Université Laval. Il a été professeur de littérature au Cégep de Rimouski. II enseigne actuellement à l'UQAR où il assume la direction du programme de maîtrise en Études littéraires. Il est membre du comité de rédaction des revues Urgences et Portée. Auteur et critique littéraire, il a publié des articles dans plusieurs revues et périodiques, des recueils de texte de création (Poèmes de la mer pays (1976), Forges froides (1977), Le mot à mot (1983), En tout état de corps (1985), Les noms du père (1985) et Coqs à deux têtes (1987), ainsi que La partie et le tout: parcours de lecture chez Fernand Ouellette et Roland Giguère (1979).

\section{CLAUIDE METTRA}

Né à Villersexel en 1922, il a fait ses études à l'Institut des Hautes études cinématographiques. Après avoir été acteur, il a travaillé dans le domaine de l'édition, et comme historien. Il a ensuite oeuvré comme critique à l'Express 
et aux Nouvelles littéraires. Il est actuellement producteur d'émissions de radio à France Culture. II a publié Saturne ou l'herbe des âmes, La chanson du Nibelungen, et Celle qui rêvait sous l'algue (1985).

\section{RAYMOND MONTPETIT}

Né à Montréal, il est diplômé en philosophie, lettres modernes et esthétique; il a étudié aux universités de Paris X et Paris VIII, et à I'Université de Montréal. Il a fondé et dirigé le Groupe de recherche en art populaire. Il est actuellement professeur au département d'histoire de l'art et vice-doyen au secteur des Arts de I'UQAM. II collabore régulièrement à plusieurs périodiques (Revue d'esthétique, Voix et images, Philosophique V, etc.), et a publié, entre autres, Comment parler de la littérature (1976), Le temps des fêtes au Québec (1978), et Sports et divertissements populaires à Montréal au XIXè siècle (1976). Il a en outre collaboré à l'organisation de plusieurs expositions dont «Le labyrinthe de l'histoire» et "Sports et divertissement populaires».

\section{CHRISTIAN MORRISSONNEAU}

Né à Québec, il a obtenu un doctorat en géographie de l'Université McGill. Entre 1976 et 1981, il a été professeur et chercheur au Centre d'études nordiques de I'Université Laval. Il enseigne actuellement la géographie à I'UQAM. Il est président du Conseil de la culture de Lanaudière. Il collabore régulièrement à plusieurs périodiques (Cahiers de géographie du Québec, Recherches sociologiques, Etudes littéraires, Etudes françaises, etc,) et a publié La société de géographie du Québec (1971), Le langage géographique de Cartier et Champlain (1978), et La terre promise, le mythe du nord québécois (1978).

\section{JACQUES PELLETIER}

Né à Québec, il détient un doctorat en littérature de l'Université d'Aix-en Provence. Il est actuellement directeur du département d'Etudes littéraires de I'UQAM et dirige Les cahiers du département d'études littéraires. Bon nombre de ses recherches ont porté sur l'oeuvre de Lawrence Durrell. Il a publié Lecture politique du roman contemporain québécois (1984), et collaboré à L'avant-garde culturelle et littéraire des années soixante-dix au Québec.

\section{ROBERT RICHARD}

Né en 1946, il a étudié en lettres françaises à l'Université Carleton et à l'Université d'Ottawa. Il a également fait des études de musique au Conservatoire de Paris. Il est actuellement professeur de littérature à l'Université Carleton. Il a donné de nombreuses conférences reliées à la littérature et aux arts visuels, dans la perspective de la psychanalyse. En 1984, il a participé à 
un séminaire de psychanalyse et psychologie à l'Université McGill. ll a été critique musical pour Vie des arts, Encyclopedia of Musician Canada, Ottawa citizen, etc., et participé à de nombreux ouvrages, dont le Dictionnaire des oeuvres littéraires du Québec.

\section{FREDERIC-JACQUES TEMPLE}

Né à Montpellier, il s'est d'abord intéressé à la spéléologie et à la préhistoire. Dans les années quarante, il a participé à la revue Fontaine, à Tam et à Alger-magazine. Il a publié, depuis cette époque, Seul à bord (1945), Sur mon cheval (1946), plusieurs recueils de poèmes dont Les oeufs de sel, Foghom, Un long voyage, et Cosmiques, et des romans dont Les eaux mortes et Un cimetière indien.

\section{BILL VAZAN}

Né à Toronto en 1933, il a étudié à Danforth Technical School de Toronto, au Ontario college of Art, à l'Ecole des Beaux-Arts de Paris et à l'Université Sir Georges Williams de Montréal. Il a contribué à la fondation de la galerie d'art Véhicule de Montréal. II est actuellement directeur de la galerie Optica et professeur à l'UQAM. Il a développé le concept du «Land art» et réalise des dessins monumentaux. 